\title{
Effect of sulphapyridine, 5-aminosalicylic acid, and placebo in patients with idiopathic proctitis: a study to determine the active therapeutic moiety of sulphasalazine
}

\author{
P A M VAN HEES, * J H BAKKER AND J H M VAN TONGEREN \\ From the Department of Medicine, Division of Gastroenterology and Department of Pharmacy, St. Radboud \\ Hospital, University of Nijmegen, Nijmegen, The Netherlands
}

SUMmARY Suppositories of sulphapyridine, 5-aminosalicylic acid, and placebo were used in 45 patients with idiopathic proctitis to determine the active part of sulphasalazine. Each patient used one of the suppositories twice daily for four weeks in a double-blind controlled trial. Complete clinical remission with normal rectal mucosa on sigmoidoscopy occurred in $60 \%$ of patients given 5 -aminosalicylic acid, but in only $13 \%$ and $27 \%$ of those given sulphapyridine and placebo respectively. Twelve patients were included twice. In eight of these patients 5-aminosalicylic acid was given one time and sulphapyridine (two patients) or placebo (six patients) another time. Clinical remission occurred in each patient with 5-aminosalicylic acid, but in only one patient during other therapy. The results suggest that 5-aminosalicylic acid is the active therapeutic moiety of sulphasalazine.

Salicylazosulphapyridine (Salazopyrin, sulphasalazine, SASP) is widely used in the treatment of ulcerative colitis and Crohn's disease. Several controlled trials have established its value in mild and moderately active colitis ${ }^{1.2}$ and in maintenance therapy to prevent recurrence of the disease ${ }^{3,4}$. Its value in Crohn's disease has not yet been established.

SASP is composed of sulphapyridine (SP) in azo linkage with 5-aminosalicylic acid (5-ASA). After an oral dose of SASP in man, only a small fraction is absorbed in the small bowel. Most of the drug reaches the colon and is almost completely split at the diazo bond by bacterial azo-reductases into SP and 5-ASA. ${ }^{5}, 6$ SP is then mostly absorbed and partially metabolised in the liver (acetylation and glucuronidation) before excretion in the urine. Most of the 5-ASA moiety can be recovered in the faeces and only a small portion is found in the urine as the acetylated form. ${ }^{7}$

The mode of action of SASP remains unknown. As SASP is particularly effective in the treatment of

*Address for reprint requests: P A M van Hees, MD, Department of Medicine, Division of Gastroenterology, St. Radboud ${ }^{1}$ Hospital, Geert Grooteplein Z16, Nijmegen, The Netherlands.

Received for publication 1 October 1979 inflammatory disease of the large bowel, it has been suggested that one of the metabolites, rather than SASP itself, may be responsible for the drug's activity at the site of breakdown.

The present study was devised to determine the active therapeutic moiety of SASP. Since SP and 5-ASA are almost completely absorbed in the small intestine $^{5}$ it was not possible to study the effect of these compounds after oral administration in patients with inflammatory bowel disease. Therefore we investigated the effect of rectally administered SP, 5-ASA, and a placebo in patients with idiopathic proctitis. Rectal administration of SASP was felt to be inappropriate because the compound is split in the rectum.

\section{Methods}

PATIENTS

Idiopathic proctitis is defined as an inflammatory condition of the rectal mucosa of unknown cause which on sigmoidoscopic examination is limited to the rectum, above which the mucosa appears normal; the colon also appears normal on barium enema $x$-ray examination. Forty-five outpatients who fulfilled these criteria were included in the trial. The study was carried out in accordance with the 
Helsinki Declaration. Patients who had had some form of therapy during the previous month were excluded. Investigations before entry to the trial included a sigmoidoscopy and barium enema, as well as measurement of the haemoglobin, ESR, leucocytes, and serum albumin and cultures of the stools.

All patients had rectal bleeding and inflamed rectal mucosa which did not improve spontaneously. There were no systemic manifestations of inflammation.

The sigmoidoscopic appearances before and after treatment were graded according to a modified scheme of Baron et al. ${ }^{8}$

Grade 0: normal mucosa.

Grade 1: mild proctitis with a hyperaemic, friable mucosa and loss of the normal vascular pattern but without spontaneous bleeding, pus or ulcers.

Grade 2: moderately severe proctitis with spontaneous bleeding and small amounts of mucus and/ or pus but without ulcers.

Grade 3: severe proctitis with ulcers and an excess of mucus and/or pus.

The patients were randomly divided into three therapeutic groups, each of which included 15 patients: placebo suppositories containing $2.75 \mathrm{~g}$ Estarine B (Adeps Solidus DAB); 5-ASA suppositories containing $200 \mathrm{mg} 5$-ASA in $2.75 \mathrm{~g}$ Estarine $\mathrm{B}$, and SP suppositories containing $300 \mathrm{mg}$ SP in $2.75 \mathrm{~g}$ Estarine B. These doses of active drug were chosen because these quantities are present in $0.5 \mathrm{~g}$ of SASP. The study was conducted as a doubleblind trial. In all patients the double-blind character could be maintained during the whole trial period. The patients used one suppository twice daily for four weeks and they were instructed to insert the suppositories and remain lying on their left side for at least one hour. The patients were examined after two and four weeks as outpatients and 24-hour samples of urine were collected to measure SP and 5-ASA content. This served to check drug intake. These determinations were made after the trial. SP was determined by the method of Hansson and Sandberg ${ }^{9}$ and 5-ASA by a modified method of Pieniaszek and Bates. ${ }^{10}$ Sigmoidoscopic examinations were performed before and at the end of the trial period. All outpatient and sigmoidoscopic examinations were done by the same person $(\mathrm{PvH})$.

At the end of the trial period, after sigmoidoscopy was done, patients were asked to indicate their clinical progress by choosing one of the following words: no symptoms, distinct improvement, unchanged, or worsened. The treatment was rated as successful if there was a complete disappearance of clinical symptoms and a normal rectal mucosa at sigmoidoscopy.

Of the 45 patients who took part in the trial 21 patients were included once and 12 patients twice (during a relapse of their proctitis). Details of the three groups of patient are given in Table 1. They were comparable in age, first attack or relapse, and duration of symptoms but not comparable with respect to sex distribution and severity of mucosal changes.

The results were analysed with the aid of the $\%^{2}-$ and sign test.

\section{Results}

Table 2 shows the change in patients' symptoms and Table 3 the change in the sigmoidoscopic appearances after treatment for four weeks. All patients who had a normal rectal mucosa at sigmoidoscopy were also free of symptoms, so that the effect of therapy in these patients could be rated as successful (Table 4). The proportion of patients with a complete clinical remission in the 5-ASA group was much higher than in the SP and placebo groups $(\mathrm{P}=\mathbf{0} \cdot \mathbf{0 2 0})$.

Table 1 Clinical details of patients with idiopathic proctitis

\begin{tabular}{|c|c|c|c|}
\hline & \multicolumn{2}{|c|}{ Type of suppository } & \multirow[b]{2}{*}{ Flacebo } \\
\hline & $5-A S A$ & $S P$ & \\
\hline Number of paticats & 15 & 15 & 15 \\
\hline Mean age (years) & $34(20-51)$ & $36(22-55)$ & $39(20-54)$ \\
\hline \multicolumn{4}{|l|}{ Sex: } \\
\hline Male/female & $2 / 13$ & $8 / 7$ & $10 / 5$ \\
\hline \multicolumn{4}{|l|}{ Condition: } \\
\hline First attack & 2 & 2 & 1 \\
\hline Relapse & 13 & 13 & 14 \\
\hline \multicolumn{4}{|l|}{ Duration of symptoms } \\
\hline before therapy (months) & $2 \cdot 7(0 \cdot 5-12)$ & $3 \cdot 2(0 \cdot 5-16)$ & $2 \cdot 5(0 \cdot 5-6)$ \\
\hline \multicolumn{4}{|l|}{ Extent of inflammation } \\
\hline before therapy $(\mathrm{cm})$ & $12 \cdot 0(7-20)$ & $12 \cdot 3(6-18)$ & $11 \cdot 0(5-15)$ \\
\hline \multicolumn{4}{|l|}{ Sigmoido;copic appearance } \\
\hline Grade 1 & 0 & 3 & 2 \\
\hline Grade 2 & 9 & 8 & 10 \\
\hline Grade 3 & 6 & 4 & 3 \\
\hline
\end{tabular}

Grade $1=$ mild proctitis. Grade $2=$ moderately severe proctitis. Grade $3=$ severe proctitis. 
Table 2 Clinical progress after treatment for four weeks

\begin{tabular}{|c|c|c|c|}
\hline & \multicolumn{3}{|c|}{ Type of suppository } \\
\hline & $\begin{array}{l}5-A S A \\
(n=15)\end{array}$ & $\begin{array}{l}S P \\
(n=15)\end{array}$ & $\begin{array}{l}\text { Placebo } \\
(n=15)\end{array}$ \\
\hline No symptoms & 9 & 2 & 4 \\
\hline Improved & 1 & 1 & 0 \\
\hline Unchanged & 4 & 9 & 7 \\
\hline Worse & 1 & 3 & 4 \\
\hline
\end{tabular}

Table 3 Sigmoidoscopic appearance after treatment for four weeks

\begin{tabular}{|c|c|c|c|}
\hline & \multicolumn{2}{|c|}{ Type of suppository } & \multirow[b]{2}{*}{$\begin{array}{l}\text { Placebo } \\
(n=15)\end{array}$} \\
\hline & $\begin{array}{l}5-A S A \\
(n=15)\end{array}$ & $\begin{array}{l}S P \\
(n=15)\end{array}$ & \\
\hline Normal & 9 & 2 & 4 \\
\hline Improved & 2 & 2 & 1 \\
\hline Unchanged & 4 & 9 & 8 \\
\hline Worse & 0 & 2 & 2 \\
\hline
\end{tabular}

Table 4 Results of treatment with 5-ASA, SP, and placebo

\begin{tabular}{|c|c|c|c|c|}
\hline \multirow{2}{*}{$\begin{array}{l}\text { Type of } \\
\text { suppository }\end{array}$} & \multirow{2}{*}{$\begin{array}{l}\text { Patients } \\
\text { (no.) }\end{array}$} & \multicolumn{2}{|c|}{ Patients in remission } & \multirow{2}{*}{$\begin{array}{l}\text { Significance of } \\
\text { differences }\end{array}$} \\
\hline & & (no.) & $(\%)$ & \\
\hline $\begin{array}{l}\text { 5-ASA } \\
\text { SP } \\
\text { Placebo }\end{array}$ & $\begin{array}{l}15 \\
15 \\
15\end{array}$ & $\begin{array}{l}9 \\
2 \\
4\end{array}$ & $\left.\begin{array}{l}60 \\
13 \cdot 3 \\
26 \cdot 7\end{array}\right\}$ & $P=0.020$ \\
\hline
\end{tabular}

$\%^{2}=7 \cdot 8 ; \mathrm{DF}=2$.

Comparison between 5-ASA and SP also showed a significant difference in favour of the 5-ASA group (Fisher's exact test: $P=0 \cdot 021$ ). The difference between 5-ASA and placebo failed to reach the conventional level of significance $(P=0 \cdot 14)$. A Fisher's exact test done on a condensed version of the results-namely, comparing clinical remission on 5-ASA $(9 / 15)$ with clinical remission on SP or placebo (combined; 6/30) - yielded a $P$ value of 0.016. Of the nine patients in the 5-ASA group who had a remission, eight had moderately severe proctitis and only one severe proctitis. Of the patients in the other therapy groups who had a remission there was also only one patient with severe proctitis.

Two patients in whom administration of 5-ASA suppositories was ineffective developed ulcerative colitis a few weeks later. One of these patients had a total colectomy because medical treatment failed. In a third patient both sigmoidoscopy and barium enema examination showed extension of the inflammation into the sigmoid after four weeks 5-ASA therapy.

The change in the sigmoidoscopic appearance in 12 patients who were included twice in the trial are summarised in Table 5. In nine patients the type of therapy differed during the two periods of active
Table 5 Change in sigmoidoscopic appearance in 12 patients who were included twice in trial

\begin{tabular}{|c|c|c|c|}
\hline \multirow[b]{2}{*}{ Patient } & \multicolumn{3}{|c|}{ Sigmoidoscopic appearance } \\
\hline & $5-A S A$ & $S P$ & Placebo \\
\hline 1 & & $\begin{array}{l}3 \rightarrow 2 \\
2 \rightarrow 2\end{array}$ & \\
\hline 2 & & $1 \rightarrow 2$ & $2 \rightarrow 1$ \\
\hline $\begin{array}{l}3 \\
4\end{array}$ & $2 \rightarrow 0$ & & $\begin{array}{l}2 \rightarrow 2 \\
2 \rightarrow 2 \\
2 \rightarrow 3\end{array}$ \\
\hline 5 & $2 \rightarrow 0$ & $2 \rightarrow 2$ & \\
\hline 6 & $2 \rightarrow 0$ & & $2 \rightarrow 1$ \\
\hline 7 & $2 \rightarrow 0$ & & $2 \rightarrow 2$ \\
\hline 8 & $2 \rightarrow 0$ & $2 \rightarrow 0$ & \\
\hline 9 & $2 \rightarrow 0$ & & $2 \rightarrow 2$ \\
\hline 10 & $2 \rightarrow 0$ & & $2 \rightarrow 1$ \\
\hline 11 & $2 \rightarrow 0$ & & $2 \rightarrow 2$ \\
\hline 12 & & $\begin{array}{l}3 \rightarrow 2 \\
2 \rightarrow 1\end{array}$ & \\
\hline
\end{tabular}

proctitis. These patients could therefore serve as their own controls. These results indicate that 5-ASA therapy is superior to placebo. Of six patients treated with both 5-ASA and placebo, six had a complete clinical remission during 5-ASA and none during placebo (sign test: $\mathbf{P}<0.05$ ).

In all the patients in the SP and 5-ASA group, SP and 5-ASA was demonstrable in the urine, respectively. After four weeks' therapy, SP excretion in 24-hour urine ranged from 47 to $181 \mathrm{mg}$ (mean $\pm \mathrm{SD} ; 110 \pm 55 \mathrm{mg}$ ). In patients on 5-ASA therapy, the 5-ASA excretion ranged from 28 to $204 \mathrm{mg}$ (mean $\pm \mathrm{SD} ; 93 \pm 59 \mathrm{mg}$ ). No SASP, SP, or 5-ASA was demonstrable in the urine of the patients in the placebo group.

\section{Discussion}

The results of this study suggest that 5-ASA is the therapeutically active moiety of SASP. SP was no more effective than a placebo.

Idiopathic proctitis is generally considered to be the same disease as ulcerative colitis, which is localised to the rectum. ${ }^{11-15}$ After oral administration SASP is almost completely split into SP and 5-ASA by colonic bacteria. 5-ASA is largely recovered in the stools. ${ }^{7}$ It may therefore be assumed that in ulcerative colitis, too, SASP is active because of a local effect of 5-ASA.

Our findings accord with those of Azad Khan et al. ${ }^{16}$ These authors investigated the effect of locally administered SASP, SP, and 5-ASA in 47 patients with mild or moderately severe ulcerative colitis and in 15 patients who were in clinical remission but whose colons were found to be inflamed at sigmoidoscopy.

The patients used one retention enema every night 
for two weeks, containing $2 \mathrm{~g}$ SASP, $1 \cdot 3 \mathrm{~g} \mathrm{SP}$, or $0.7 \mathrm{~g}$ 5-ASA. Fifty-four of the 62 patients were already on maintenance therapy with 2 g SASP daily by mouth. This treatment was continued during the trial. After administration of SASP and 5-ASA, improvement was observed in about $70 \%$ of the patients, both with respect to clinical symptoms and sigmoidoscopic appearance. For SP this was $38 \%$. Pronounced histological improvement was observed in approximately $30 \%$ of the patients receiving SASP or 5-ASA and in only $5 \%$ of those receiving SP.

An objection to the study of Azad Khan et al ${ }^{16}$ is that the majority of patients continued taking a maintenance dose of SASP during the trial.

The use of SASP is not infrequently limited by the appearance of side-effects which are almost all attributable to the SP moiety. Now that it appears that 5-ASA is the active moiety of SASP and SP functions as a carrier to ensure sufficiently high concentrations of 5-ASA in the colon, it would be of great value to synthesise a new compound whereby SP is replaced by a less toxic (preferably inert) carrier. The advantage of such a medicine would be that higher doses can be administered (only a small fraction of 5-ASA is absorbed from the colon) with the possibility of better therapeutic results than those with SASP, but with fewer side-effects as a result of the absence of SP. Furthermore, time has come to investigate 5-ASA's pharmacodynamic characteristics and its mode of action in patients with inflammatory bowel disease.

The authors wish to thank Pharmacia AB, Uppsala, Sweden, for donating highly purified 5-aminosalicyclic acid.

\section{References}

${ }^{1}$ Baron JH, Connell AM, Lennard-Jones JE, Avery Jones F. Sulphasalazine and salicylazosulphadimidine in ulcerative colitis. Lancet 1962; 1: 1094-6.

2Dick AP, Grayson MJ, Carpenter RG, Petrie A.
Controlled trial of sulphasalazine in the treatment of ulcerative colitis. Gut 1976; 5: 437-42.

${ }^{3}$ Misiewicz JJ, Lennard-Jones JE, Connell AM, Baron $\mathrm{JH}$, Avery-Jones F. Controlled trial of sulphasalazine in maintenance therapy for ulcerative colitis. Lancet $1965: 1: 185-8$.

${ }^{4}$ Dissanayake AS, Truelove SC. A controlled therapeutic trial of long-term maintenance treatment of ulcerative colitis with sulphasalazine (Salazopyrin). Gut 1973: 14: 923-6.

${ }^{5}$ Schröder H, Campbell DES. Absorption, metabolism and excretion of salicylazosulfapyridine in man. Clin Pharmacol Ther 1972; 13: 539-51.

${ }^{6}$ Peppercorn MA, Goldman P. Distribution studies of salicylazosulfapyridine and its metabolites. Gastroenterology 1973; 64: 240-5.

'van Hees PAM, Tuinte JHM, van Rossum JM, van Tongeren JHM. Influence of intestinal transit time on azo-reduction of salicylazosulfapyridine (Salazopyrin). Gut 1979; 20: 300-4.

${ }^{8}$ Baron JH, Connell AM, Lennard-Jones JE. Variation between observers in describing mucosal appearances in proctocolitis. Br Med J 1964; 1: 89-92.

${ }^{9}$ Hansson KA, Sandberg M. Determination of sulphapyridine and its metabolites in biological materials after administration of salicylazosulphapyridine. Acta Pharm Suec 1973; 10: 87-92.

${ }^{10}$ Pieniaszek HJ, Jr. Bates TR. Colorimetric determination of 5-aminosalicylic acid and its $\mathrm{N}$-acetylated metabolite in urine and feces. Res Commun Chem Pathol Pharmacol 1975; 12: 571-81.

${ }^{11}$ Truelove SC. Suppository treatment of haemorrhagic proctitis. Br Med J 1959; 1, 955-8.

${ }^{12}$ Lennard-Jones JE, Cooper GW, Newell AC, Wilson CWE, Avery-Jones F. Observations on idiopathic proctitis. Gut 1962; 3: 201-6.

${ }^{13}$ Sparberg M, Fennessy J, Kirsner JB. Ulcerative proctitis and mild ulcerative colitis: a study of 220 patients. Medicine 1966; 45: 391-412.

${ }^{14}$ Farmer RG, Brown $\mathrm{CH}$. Ulcerative proctitis: course and prognosis. Gastroenterology 1966; 51 : 219-23.

${ }^{15}$ Folley JH. Ulcerative proctitis. $N$ Engl J Med 1970; 282: $1362-4$.

${ }^{16}$ Azad Khan AK, Piris J, Truelove SC. An experiement to determine the active therapeutic moiety of sulphasalazine. Lancet 1977; 2: 892-5. 